\title{
LA ATENUACIÓN COMO SIGNO DE MADUREZ DIALÓGICA EN LA CONVERSACIÓN ENTRE DON QUIJOTE Y SANCHO PANZA ${ }^{1}$
}

\author{
Marta Albelda Marco \\ Universitat de València (Grupo Val.Es.Co)
}

\section{RESUMEN}

En este artículo se realiza una primera aproximación al comportamiento del fenómeno de atenuación pragmática en el Quijote. Por un lado, se presenta una visión panorámica de los diversos mecanismos atenuantes de la novela a partir del análisis de uno de sus capítulos. Por otro lado, se estudian con más detalle los atenuantes más frecuentes en la obra, tanto los que atenúan directamente la fuerza ilocutiva (verbo dicendi unido a justificaciones, la locución hacer saber), como los que mitigan primariamente el contenido proposicional (el uso adverbial de algo y como que).

El empleo de la atenuación pone de relieve la existencia de un interlocutor, lo que destaca su carácter esencialmente interaccional y su papel fundamental en la configuración de las relaciones sociales. En este sentido, se defiende que la frecuencia y desarrollo de este fenómeno, así como la rica variedad de sus mecanismos en el Quijote, respalda la tesis de la madurez dialógica alcanzada en esta primera novela moderna.

PALABRAS CLAVE: atenuación, Quijote, madurez dialógica, conversación, novela XVII.

\section{AbSTRACT}

This article represents an initial approach to the phenomenon of pragmatic mitigation in the 17 th century Spanish novel Don Quixote. Firstly, it presents an overview of the different mitigating devices used in this novel, based on an analysis of one chapter. Secondly, it studies the mitigating elements frequently used in this novel in greater detail, taking on board those that directly mitigate the illocutionary force (e.g. a verbum dicendi accompanying a justification, the expression

${ }^{1}$ El presente trabajo ha sido realizado gracias a la financiación recibida por el Ministerio de Economía, Industria y Competitividad (Gobierno de España), a través del proyecto Es.VaG.Atenuación: «La atenuación pragmática en su variación genérica: géneros discursivos escritos y orales en el español de España y América» (FFI2016-75249-P). 
hacer saber) as well as those that primarily mitigate the propositional content (e.g. the adverbial use of algo and como que).

Mitigation highlights the presence of an interlocutor, drawing attention to its fundamentally interactional nature and its essential role in shaping social relations. Accordingly, this article argues that the frequency and highly-developed nature of this phenomenon in Don Quixote, together with the wealth and variety of mitigation devices deployed, support the thesis that this first modern novel achieved dialogic maturity.

KEYWORDS: mitigation, Quixote, dialogical maturity, conversation, 17 th century novel.

\section{INTRODUCCIÓN}

El presente trabajo, en homenaje al maestro José Jesús de Bustos Tovar, constituye un primer acercamiento al estudio de la atenuación en el Quijote, con el objetivo de respaldar la tesis de la madurez dialógica alcanzada en esta primera novela moderna (Iglesias Recuero 1998; Cano 2005; Narbona 2007, 2017; Pujante 2007). Se pretende acreditar la existencia de un fenómeno más en el conjunto de rasgos que reconocen en el Quijote la primera obra española cuyos diálogos presentan «cooperación interactiva», «discurso compartido, construido como encadenamiento de estructuras enunciativas en las que se manifiestan las distintas voces de la enunciación con plena autonomía» (Bustos Tovar 2001: 194).

De hecho, la primera fase exploratoria de este trabajo consistió en un análisis que pretendía registrar el uso de la atenuación en las cuatro obras estudiadas por Bustos Tovar (2001), situadas en la transición de la Edad Media al Renacimiento: El Corbacho (1438), La Celestina (1499), La lozana andaluza (1528) y Lazarillo de Tormes (1554). De acuerdo con Bustos Tovar (2001: 198), en estas obras ya se aprecia una «inserción de la oralidad conversacional en la escritura ${ }^{2}$. Sin embargo, un análisis piloto de estas cuatro obras mostró un escaso empleo de mecanismos atenuantes, a diferencia de lo que en una segunda fase de trabajo encontramos en el Quijote.

El exiguo recurso a la atenuación en tales obras de transición parece explicarse en dos sentidos. Por un lado, la naturaleza de sus construcciones

\footnotetext{
${ }^{2}$ Si bien más predominante en algunas que en otras. Así, el autor opone el diálogo coloquial de El Corbacho y La lozana andaluza al diálogo canónico de La Celestina y Lazarillo, apelando a que en estas últimas la «mímesis conversacional es muy secundaria» (Bustos Tovar 2001: 2005).
} 
dialógicas no está todavía plenamente desarrollada: los diálogos presentan una limitada fluidez interactiva y la organización conversacional tiende a ser todavía rígida y artificial. Por otro lado, son obras en las que, aunque se preocupan por la dinamicidad y cooperación interactiva, la función descriptiva de la lengua (aquella que busca expresar contenidos) tiene más peso que la función interactiva (que busca manifestar relaciones sociales y actitudes personales; Brown y Yule 1993, apud Bustos Tovar 2001: 193). Ambos aspectos justifican que apenas encontremos usos atenuantes en estas obras. Así pues, consideramos que para la detección de este fenómeno pragmático se hacía necesario avanzar algunos años en la historia de la literatura, por lo que se decidió analizar la novela cervantina.

La atenuación es un fenómeno pragmático, de profunda naturaleza interactiva, en tanto que su empleo pone de relieve la existencia de un interlocutor, de un tú al que va dirigido el mensaje en busca del acuerdo y la eficiencia comunicativa. Atenuar presupone negociar comunicativamente, y por ello, se atiende a la figura del otro, se vela por ella para lograr estratégicamente los fines comunicativos que el hablante se propone. Así, la atenuación se define como una estrategia de recepción comunicativa en la que se focaliza la figura del oyente, y que se lleva a cabo a través de la minimización de la fuerza ilocutiva de los actos de habla (Briz 1998, 2006; Briz y Albelda 2013).

Los procedimientos de atenuación actúan directamente sobre la fuerza ilocutiva (por ejemplo, modalizando la fuerza epistémica de una aseveración o reduciendo la fuerza directiva de una petición), o también pueden incidir primariamente sobre el contenido proposicional y secundariamente sobre la fuerza ilocutiva (Briz 1998). En este último caso se incluyen los procedimientos de lenguaje vago, en los que se difumina el contenido proposicional de lo dicho, y que permiten intencionadamente al hablante no ser claro al expresarse (Lakoff 1972; Mihatsch 2007, 2010). El español conversacional actual registra diversos mecanismos de lenguaje vago, impreciso o aproximado como algo así, como, en plan, rollo, tipo, cierto, más o menos, una especie de, etc.

En tanto que estamos ante un fenómeno pragmático, su reconocimiento solo puede ser contextual. En ese sentido, estudios más recientes han considerado la necesidad de establecer -junto con los anteriores- un criterio definitivo, común y de naturaleza contextual para la identificación de los usos atenuantes. Así, se incluye en su caracterización el hecho de que la atenuación se origina por necesidades de gestión de imagen, para proteger o reparar posibles daños o amenazas hacia los interlocutores o hacia el propio hablante (Thaler 2012; Schneider 2013; Albelda 2016).

Para la identificación de la atenuación en el Quijote, se ha diseñado la siguiente metodología. Tras una relectura de la obra, se han buscado en 
ella los procedimientos atenuantes propuestos en el listado de Albelda y Cestero (2011) y Albelda et alii (2014) ${ }^{3}$. Esta nómina recoge mecanismos candidatos a funcionar de forma atenuadora en la lengua española actual, por lo que solo se ha tomado como punto de referencia: ha sido imprescindible abrirse a la identificación de manifestaciones atenuantes propias de la lengua del siglo XVII. Para ello, junto con la identificación de posibles formas atenuantes se han estudiado los factores contextuales que inciden en la generación de usos atenuantes (Albelda et alii 2014), con especial atención a las cuestiones de implicación y gestión de la imagen social de los participantes en los diálogos.

En los siguientes apartados se ofrece, en primer lugar, una visión panorámica de los procedimientos atenuantes en la novela cervantina $(\S 1)$. Tras ello, se estudian de cerca algunos mecanismos atenuantes particulares, de especial incidencia en la obra $(\$ 2)$.

\section{LA ATENUACIÓN EN LOS DIÁlOGOS DEL QUIJOTE: UNA PRUEBA MÁS DE SU MODERNIDAD}

Una de las fronteras más notables entre la literatura anterior y la obra cervantina es precisamente la mayor presencia y riqueza de este fenómeno pragmático, cuya plasmación lingüística es altamente coincidente con muchos de los procedimientos de atenuación empleados actualmente en la lengua oral espontánea. Para un primer acercamiento general a la atenuación en el Quijote, veamos en este apartado el comportamiento y la profusión de dicho fenómeno a propósito de un análisis detallado de uno de los capítulos de la obra.

Como se ha señalado, para marcar mejor la modernidad del fenómeno atenuante en esta obra, así como su naturaleza oral, se toma como referencia el catálogo de mecanismos atenuantes presentado en Albelda y Cestero (2011) y en Albelda et alii (2014), los cuales provienen de un análisis previo del corpus de conversaciones coloquiales Val.Es.Co. (2002 y en línea) y de los corpus de entrevistas orales semidirigidas PRESEEA-Valencia y PRESEEA-Alcalá.

Se analiza el capítulo XV de la obra, y se extraen, de manera cronológica, varios fragmentos con procedimientos atenuantes. En este capítulo «se cuenta la desgraciada aventura que se topó don Quijote en topar con unos desalmados yangüeses». Veamos, en primer lugar, todos los ejemplos, y a continuación, su descripción.

\footnotetext{
${ }^{3}$ Para la extracción de ocurrencias, se ha trabajo con la versión digital de la Biblioteca virtual Miguel de Cervantes, que se basa en Ediciones de La Lectura (1911-1913). El motor de búsqueda ha facilitado el manejo de los datos.
} 
(1) ... Sucedió, pues, que a Rocinante le vino en deseo de refocilarse con las señoras facas, y saliendo, así como las olió, de su natural paso y costumbre, sin pedir licencia a su dueño, tomó un trotico algo picadillo y se fue a comunicar su necesidad con ellas; mas ellas, que, a lo que pareció, debían de tener mas gana de pacer que de ál, recibiéronle con las herraduras y con los dientes, de tal manera, que a poco espacio se le rompieron las cinchas, y quedó sin silla, en pelota. [...]

(2) Ya en esto don Quijote y Sancho, que la paliza de Rocinante habían visto, llegaban ijadeando, y dijo don Quijote a Sancho:

-A lo que yo veo, amigo Sancho, estos no son caballeros, sino gente soez y de baja ralea. Dígolo porque bien me puedes ayudar a tomar la debida venganza del agravio que delante de nuestros ojos se le ha hecho a Rocinante.

-¿Qué diablos de venganza hemos de tomar -respondió Sancho-, si estos son mas de veinte, y nosotros no mas de dos, y aun quizá, nosotros sino uno y medio?

-Yo valgo por ciento -replicó don Quijote.

Y sin hacer mas discursos, echó mano a su espada y arremetió a los yangüeses. $[\ldots]$

(3) -¿Qué quieres, Sancho hermano? -respondió don Quijote, con el mesmo tono afeminado y doliente que Sancho.

-Querría, si fuese posible -respondió Sancho Panza-, que vuestra merced me diese dos tragos de aquella bebida del feo Blas, si es que la tiene vuestra merced ahí a mano: quizá será de provecho para los quebrantamientos de huesos, como lo es para las feridas. [...]

(4) ... dijo el molido caballero don Quijote- [...] y así, creo que en pena de haber pasado las leyes de la caballería, ha permitido el Dios de las batallas que se me diese este castigo. Por lo cual, Sancho Panza, conviene que estés advertido en esto que ahora te diré, porque importa mucho a la salud de entrambos; y es que cuando veas que semejante canalla nos hace algún agravio, no aguardes a que yo ponga mano al espada para ellos, porque no lo haré en ninguna manera; sino pon tú mano a tu espada y castígalos [...].

(5) Mas no le pareció tan bien a Sancho Panza el aviso de su amo, que dejase de responder, diciendo:

-Señor, yo soy hombre pacífico, manso, sosegado, y sé disimular cualquiera injuria, porque tengo mujer y hijos que sustentar y criar. Así que, séale a vuestra merced también aviso, pues no puede ser mandato, que en ninguna manera pondré mano a la espada, ni contra villano ni contra caballero, y que desde aquí para delante de Dios perdono cuantos agravios me han hecho y han de hacer. [...]

(6) A esto replicó el escudero:

-Señor, ya que estas desgracias son de la cosecha de la caballería, dígame vuestra merced si suceden muy a menudo, o si tienen sus tiempos limi- 
tados en que acaecen; porque me parece a mí que a dos cosechas quedaremos inútiles para la tercera, si Dios, por su infinita misericordia, no nos socorre.

(7) -Sábete, amigo Sancho -respondió don Quijote-, que la vida de los caballeros andantes está sujeta a mil peligros y desventuras $[\ldots \mathrm{H}]$ ay un autor secreto, y de no poco crédito, que dice que, habiendo cogido al Caballero del Febo con una cierta trampa [...]. Ansí, que bien puedo yo pasar entre tanta buena gente; que mayores afrentas son las que éstos pasaron que no las que ahora nosotros pasamos. Porque quiero hacerte sabidor, Sancho, que no afrentan las heridas que se dan con los instrumentos que acaso se hallan en las manos, y esto está en la ley del duelo, escrito por palabras expresas: que si el zapatero da a otro con la horma que tiene en la mano, puesto que verdaderamente es de palo, no por eso se dirá que queda apaleado aquel a quien dio con ella. Digo esto porque no pienses que, puesto que quedamos desta pendencia molidos, quedamos afrentados: porque las armas que aquellos hombres traían, con que nos machacaron, no eran otras que sus estacas, y ninguno dellos, a lo que se me acuerda, tenía estoque, espada ni puñal.

(8) ... Siempre deja la ventura una puerta abierta en las desdichas, para dar remedio a ellas -dijo don Quijote-. Dígolo porque esa bestezuela podrá suplir ahora la falta de Rocinante, llevándome a mí desde aquí a algún castillo donde sea curado de mis feridas. Y mas, que no tendré a deshonra la tal caballería, porque me acuerdo haber leído que aquel buen viejo Sileno, ayo y pedagogo del alegre Dios de la risa, cuando entró en la Ciudad de las cien puertas iba, muy a su placer, caballero sobre un muy hermoso asno.

-Verdad será que él debía de ir caballero, como vuestra merced dice -respondió Sancho-; pero hay grande diferencia del ir caballero al ir atravesado como costal de basura.

A continuación, se explican y clasifican los mecanismos atenuantes de los extractos. Aunque nuestro principal interés es observar la atenuación en los diálogos de don Quijote y Sancho, también se han tomado en consideración las palabras del narrador omnisciente, en tanto que en su prosa narrativa emplea atenuantes. De hecho, en el extracto (1) tenemos precisamente la voz del narrador, que recurre a atenuantes proposicionales para explicar el capricho de Rocinante por recrearse con unas yeguas, lo que desencadena una pelea de su dueño y Sancho con los yangüeses. En este fragmento, destacan los procedimientos de lenguaje vago: los eufemismos de la perífrasis «venir en deseo» y «comunicar su necesidad con ellas»; el empleo del indefinido algo modificador de imprecisión del adjetivo y los diminutivos de «trotico»y «picadillo». En este caso, los atenuantes suponen un guiño humorístico del narrador al describir con maneras indirectas la conducta libertina del rocín. 
En el extracto (2), ambas intervenciones, de don Quijote y Sancho, presentan atenuantes directos de la fuerza ilocutiva. La intervención del caballero incluye dos actos de habla: el primero es una afirmación precedida por un acotador de la opinión a la persona del hablante («a lo que yo veo»), se atenúa, pues, la fuerza ilocutiva asertiva; el segundo acto es una petición de ayuda a Sancho para resarcir el agravio, que precisamente se atenúa a través del acto anterior, mediante la justificación expresada por el verbo dicendi («dígolo porque»). Por su parte, Sancho, expresa una respuesta despreferida a la petición de su amo: manifiesta desacuerdo y rechaza la idea de vengarse. Por su posición de inferioridad jerárquica y para proteger su propia imagen necesita hacer uso de atenuantes: por un lado, expresa indirectamente la negativa mediante una pregunta retórica y emplea el adverbio epistémico de probabilidad quizá y la expresión «(somos) uno y medio» para expresar que su fuerza es menor, incluso, que la de dos personas.

De nuevo, en el extracto (3) tenemos una atenuación del acto directivo de petición, ahora por parte de Sancho. Son cuatro los mecanismos que el escudero emplea para pedir una medicina curativa a su señor, todos ellos de uso general y corriente también en la lengua hablada de hoy: el empleo del verbo modal querer en condicional, las dos construcciones sintácticas condicionales, que, al introducir posibilidad, en estos ejemplos sirven para reducir la fuerza ilocutiva («si fuese posible»; «si es que la tiene...»); la justificación introducida por el adverbio de posibilidad quizá.

En el extracto (4) se utiliza la fórmula atenuada de necesidad deóntica «conviene que», en la que se borra el agente de la acción verbal para objetivar la advertencia que le sigue. En (5) Sancho opta por expresar una fuerza ilocutiva de menor impacto en la escala de las fuerzas directivas: en lugar de mandato indica que está realizando un aviso, pues no se lo permite de otra manera su estatuto jerárquico («séale a vuestra merced también aviso, pues no puede ser mandato»). Se trata de un contenido despreferido para su interlocutor, puesto que rechaza acudir a la violencia, petición que en su turno anterior don Quijote le ha hecho (véase 5: «... sino pon tú mano a tu espada y castígalos»).

En el extracto (6) Sancho mitiga, por un lado, la petición de información a su amo mediante una justificación de por qué la formula, y por otro, mitiga su opinión sobre el destino que considera les depara a ambos; lo hace a través de un verbo epistémico débil (parecer) y mediante una acotación de la opinión a la propia persona mediante los pronombres personales.

El fragmento (7) reúne diversos elementos de mitigación en boca de don Quijote. Por una parte, emplea una litote al referirse a la historia de las novelas caballerescas («de no poco crédito»). Recurre en este fragmento a un mecanismo muy abundante en la novela, que se tratará con más detalle en el siguiente apartado, y que constituye una forma de modalizar la aserción: «sábete, amigo Sancho», «porque quiero hacerte sabidor, San- 
cho, ...». En lugar de expresar la información o el consejo directamente lo introduce con una apelación al conocimiento del que el interlocutor necesita disponer.

De nuevo, en (7) hace uso de la justificación del decir ante su interlocutor («digo esto porque no pienses que»), al igual que ocurre también en el fragmento (8) ("dígolo porque esta bestezuela»), para introducir la petición de que el asno de Sancho lleve a Quijote a curar las heridas. Asimismo, en (8) también se puede aceptar el valor atenuante de la fórmula concesiva de Sancho («verdad será ... pero»): la concesión parcial de la primera parte atenúa la segunda, en la que se ofrece un contenido amenazante para la imagen del interlocutor.

Este análisis de un capítulo de la obra nos permite constatar que el recurso a la atenuación es muy habitual en la novela y que se manifiesta a través de variados procedimientos, la mayoría de ellos también vigentes en la lengua hablada del siglo XxI. Como se advierte, excepto en el fragmento (1) del narrador, en las intervenciones del caballero y el escudero la atenuación se encuentra al servicio del mantenimiento de una adecuada relación interpersonal entre ambos. Se emplea para suplir o acompañar los contenidos que pueden causar una amenaza o menoscabo al territorio o imagen del interlocutor: en peticiones, en rechazos a las peticiones o desacuerdos, en la exposición de enseñanzas (habitualmente opiniones) de don Quijote a su escudero.

Criado de Val (2005: 30) señala que el «rasgo esencial del diálogo cervantino es la "cordialidad" entre Don Quijote y Sancho». Al mismo tiempo, también reconoce una «competencia personal entre los interlocutores»:

En todo diálogo, por cordial que sea, hay una oposición que no es de puntos de vista sino de jerarquía, el predominio personal de uno u otro interlocutor. Don Quijote no es solo el hidalgo, también el sabio, frente a su escudero que se reconoce a sí mismo ignorante y cerrado de inteligencia. Hay, no obstante, algunos temas en los que esta relación se alterna y el escudero domina al señor (Criado de Val 2005: 31).

La atenuación, como estrategia de relación interpersonal, sirve a ambos propósitos. Permite mantener la cordialidad entre ellos, pues suaviza y repara los conflictos y desavenencias debidas a las opiniones y distintas visiones de los asuntos. También acorta las distancias provenientes del diferente estatuto jerárquico sustentado por cada interlocutor, al igual que sus posibles vulneraciones.

\section{Algunos Procedimientos atenuantes de especial Relieve En El QuiJote}

Se ha seleccionado un conjunto de procedimientos atenuantes de especial relieve en el Quijote para estudiar con más profundidad su compor- 
tamiento en la novela cervantina. Por un lado, nos detendremos en un grupo de mecanismos de reducción directa de la fuerza ilocutiva (atenuantes pragmáticos o atenuación del modus, de acuerdo con Briz 1998) y, por otro lado, trataremos una serie de atenuantes del contenido proposicional, que reducen secundariamente la fuerza ilocutiva (atenuantes semánticopragmáticos o atenuación del dictum, de acuerdo con Briz 1998).

\subsection{Atenuación de las aserciones mediante la explicitud de la intención comunicativa: decir $y$ hacer saber}

En los fragmentos anteriores (2), (7) y (8) hemos visto una fórmula de atenuación muy frecuente en la obra, la justificación del decir, considerada también atenuante en usos actuales (Albelda y Cestero 2011; Contreras 2012: 457; Albelda et alii 2014). Su patrón es el siguiente:

\section{Aserción/Opinión $[\mathrm{A}]+$ dígolo/digo esto porque + \\ Petición/Aserción/Opinión [B]}

El pronombre deíctico, $\mathrm{CD}$ de decir, presenta un valor anafórico, se refiere al acto de habla previo (A). A este le sigue una proposición causal (B) cuya función es justificar la enunciación del acto asertivo u opinativo anterior, y por tanto, lo atenúa. A su vez, se lleva a cabo otra atenuación, precisamente realizada por el enunciado previo (A), el cual se constituye como justificación al acto que seguirá al porque (acto B). Así, en el anterior fragmento (2), se justifica la enunciación (el decir) del acto previo «estos no son caballeros, sino gente soez y de baja ralea» (A) a través del enunciado posterior «dígolo porque bien me puedes ayudar a tomar la debida venganza del agravio» (B, es una petición). Y, al mismo tiempo, el enunciado posterior (B) es la justificación del hecho de decir el acto previo (A); es una causal de la enunciación (Lapesa 1978; Narbona 2015). En este sentido, bien podemos considerar este como un patrón de mutua atenuación, como se muestra en la siguiente figura:

A justifica lo dicho en $B$

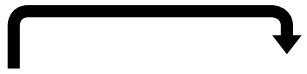

A. Dígolo porque B

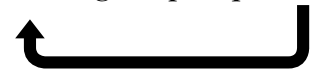

B justifica el acto de decir A 
En los ejemplos con decir de (7) y (8) encontramos el mismo mecanismo de atenuación mostrado en el gráfico anterior. Se registra también en el Quijote con bastante frecuencia otro uso de digo con valor atenuante, distinto al anterior. Véase el siguiente fragmento (9):

(9) -¡Ah! -dijo Sancho-. [...] De donde se viene a sacar, que los que no comen, ni beben, ni duermen, ni hacen las obras naturales que yo digo, estos tales están encantados; pero no aquellos que tienen la gana que vuestra merced tiene, y que bebe cuando se lo dan, y come cuando lo tiene, y responde a todo aquello que le preguntan.

-Verdad dices, Sancho -respondió don Quijote-; pero ya te he dicho que hay muchas maneras de encantamentos, y podría ser que con el tiempo se hubiesen mudado de unos en otros, y que agora se use que los encantados hagan todo lo que yo hago, aunque antes no lo hacían. De manera, que contra el uso de los tiempos no hay que argüir ni de qué hacer consecuencias. Yo sé y tengo para mí que voy encantado, y esto me basta para la seguridad de mi conciencia; que la formaría muy grande si yo pensase que no estaba encantado y me dejase estar en esta jaula perezoso y cobarde $[\ldots]$.

-Pues, con todo eso -replicó Sancho-, digo que para mayor abundancia y satisfación, sería bien que vuestra merced probase a salir desta cárcel, que yo me obligo con todo mi poder a facilitarlo, y aun a sacarle della, y probase de nuevo a subir sobre su buen Rocinante, que también parece que va encantado...

(Capítulo XLIX)

En este fragmento Sancho reprocha a don Quijote considerarse encantado. El caballero le rebate que hay diversos tipos de encantamiento y que está seguro del suyo. En la tercera intervención, Sancho no acepta la explicación de su amo y le insta, también de manera atenuada (en forma de consejo, «sería bien que...») a que abandone la idea del encantamiento. Introduce su consejo -que, entendemos, amenaza la imagen de don Quijote- con el verbo dicendi digo. En este caso, a diferencia de los ejemplos vistos anteriormente con el pronombre anafórico (lo, esto, ejemplos 2, 7 y 8), el contenido del CD del verbo no es previo al verbo decir sino posterior («sería bien que vuestra merced probase...»).

Ahora la atenuación que lleva a cabo el digo ya no es una mutua atenuación, puesto que no tenemos la proposición causal con el porque. Sin embargo, se aprecia que la propia explicitud del verbo dicendi, frente a la formulación del mismo enunciado sin este, le otorga un valor atenuante: «un valor de atenuación que muestra lo dicho por el hablante como una opinión propia más que como una afirmación indiscutible» (Fuentes Rodríguez 1990: 112; véase también Fant 2007). Se trata de un elemento que restringe el alcance de lo dicho (en este caso, una opinión que puede amenazar a la imagen del interlocutor) al propio hablante, para que no se en- 
tienda como una generalización ${ }^{4}$. A diferencia de otros valores que puede expresar digo, en este fragmento su valor se acerca más al modal, que hoy en día se emplea habitualmente en posición final o, en general, en posición parentética, muchas veces con el sujeto explícito en posición posterior, digo yo. En este sentido, Reig (2007: 187) señala para usos actuales similares al registrado en el Quijote y ejemplificado en (9), que «resultan pragmáticamente extraños en la conversación; por el contrario, los enunciados realizativos con estos verbos son frecuentes en los documentos administrativos y jurídicos para realizar una aseveración o una petición» ${ }^{5}$.

Junto con el digo aparece con bastante frecuencia en el Quijote la locución hacer saber ${ }^{6}$ con el valor de 'informar' o 'comunicar', que presenta diversas variantes, como puede verse abajo en los ejemplos: hágote saber (10), te hago saber (11), has de saber (12), te quiero hacerte sabidor (anterior ejemplo 7), quiérote hacer sabidor. De nuevo, se hace explícita la fuerza ilocutiva de comunicación, no siendo imprescindible para que tenga lugar el propio acto de comunicación. Se emplea en la mayoría de los usos registrados por parte de don Quijote y, casi siempre, para dirigirse a Sancho y transmitirle alguna lección. De hecho, los enunciados que a esta locución se subordinan son generalizaciones y verdades con carácter de adoctrinamiento, como puede verse en los extractos de abajo. En ese sentido, y dada su alta frecuencia en la novela ${ }^{7}$, puede considerarse que manifiestan un alto grado de convencionalización al servir de señales lingüísticas de introducción de enseñanzas. Y en esta explicitud de la intención de enseñar radica principalmente el valor atenuante de ese procedimiento.

La enseñanza expuesta por don Quijote no se transmite como una afirmación categórica suya (Meyer-Hermann 1988), proveniente de su opinión. El verbo de comunicación introductor (hacer saber) permite crear un juego

4 Obsérvese que estamos ante un uso metalingüístico, que no realizativo del verbo (Reig 2006; Benavent 2015), puesto que, aunque aparece con la forma típica de los verbos realizativos, «no es preciso comunicar que se está realizando un acto como decir o repetir para que se identifique como tal» (Reig 2006: 189). En ese sentido, aunque le sigue un que, no se trata de discurso reproducido indirecto, puesto que ni está formulado en pasado ni refiere a una cita proferida en una situación anterior. En la misma obra aparecen usos del digo con otros valores: reformulador, intensificador (en los que se reivindica la voz del hablante o se pretende dar autoridad a lo que se dice), etc.

${ }^{5}$ Este es el ejemplo de documento administrativo, recogido por la autora para los casos en que hoy en día se emplea este uso de digo: «....ante esta Delegación Provincial de Trabajo, comparezco y, como mejor proceda en Derecho, respetuosamente digo: ...» (Reig 2007: 187).

${ }^{6}$ La NGLE (RAE) la considera perífrasis verbal con el significado de 'informar' en $\$ 26.10 o$ y como locución verbal con el significado de 'comunicar' en $\$ 28.4 q$.

${ }^{7}$ Humpolíková (2014: 38) destaca la abundancia de esta "construcción factitiva» (como la autora la considera) en el Quijote, y concluye que es «una característica intrínseca de la obra». 
de polifonías, que, de hecho, son muy frecuentes en la novela (Narbona $2006)^{8}$ : en este caso, se oculta la autoría del mensaje transmitido, haciéndose pasar como una verdad compartida y conocida a priori, lo que a su vez supone que existe de manera ajena e independiente a la opinión o subjetividad del que la dice. A ello se une el valor léxico de la locución, de tipo factitivo o causativo: el sujeto no ejecuta por sí la acción sino que la hace ejecutar por otro. El hablante al emplearlo rebaja la responsabilidad respecto a lo dicho, pues solo participa en la acción (Iglesias Bango 1992; Humpolíková 2014).

Además, en ejemplos como el de (12) se une la perífrasis de obligación, «has de saber», que en este caso redunda en el efecto atenuante, pues se introduce el valor modal deóntico, que desfocaliza al hablante como responsable de la acción y la traspasa a una necesidad objetiva externa:

(10) -Aquí trayo una cebolla, y un poco de queso, y no sé cuántos mendrugos de pan -dijo Sancho-; pero no son manjares que pertenecen a tan valiente caballero como vuestra merced.

-¡Qué mal lo entiendes! -respondió don Quijote-: hágote saber, Sancho, que es honra de los caballeros andantes no comer en un mes, y, ya que coman, sea de aquello que hallaren más a mano.

(Capítulo x)

(11) -No me dieron a mí lugar -respondió Sancho- a que mirase en tanto; porque, apenas puse mano a mi tizona, cuando me santiguaron los hombros con sus pinos, de manera, que me quitaron la vista de los ojos y la fuerza de los pies, dando conmigo adonde ahora yago, y adonde no me da pena alguna el pensar si fue afrenta, o no, lo de los estacazos, como me la da el dolor de los golpes, que me han de quedar tan impresos en la memoria como en las espaldas.

-Con todo eso, te hago saber, hermano Panza -replicó don Quijote-, que no hay memoria a quien el tiempo no acabe, ni dolor que muerte no le consuma.

(Capítulo Xv)

(12) No estoy para responder -respondió Sancho- $[\ldots]$ yo pondré silencio en mis rebuznos; pero no en dejar de decir que los caballeros andantes huyen, y dejan a sus buenos escuderos molidos como alheña, o como cibera, en poder de sus enemigos.

-No huye el que se retira -respondió don Quijote-; porque has de saber, Sancho, que la valentía que no se funda sobre la base de la prudencia se llama temeridad, y las hazañas del temerario más se atribuyen a la buena

8 «Todo texto es polifónico, ya que siempre se advierte la presencia de varias voces, y el Quijote lo es en grado sumo, al explotar sabiamente Cervantes todos los procedimientos para asumir, compartir y distribuir la responsabilidad de hablar o escribir» (Narbona 2006: 162). 
fortuna que a su ánimo. Y así, yo confieso que me he retirado, pero no huido; $y$ en esto he imitado a muchos valientes...

(Capítulo XXVIII)

\title{
2.2 Atenuación del contenido proposicional: la vaguedad expresada por algo y como (que)
}

En el análisis de la atenuación del capítulo xv del Quijote (§1), junto con los atenuantes que afectan directamente al decir (del modus), se obtuvieron atenuantes del contenido proposicional (del dictum), que modifican semántico-pragmáticamente lo dicho y secundariamente el decir (Briz 1998, 2006). En coincidencia con los mecanismos listados en Albelda et alii (2014) para el español actual, se registró el diminutivo, el eufemismo, el uso adverbial de algo con valor indefinido (extracto 1) y la litote (extracto 7).

Junto con el diminutivo, uno de los procedimientos más habituales de expresión de lenguaje vago con función atenuante es el empleo de algo acompañando a adjetivos. Además de su valor pronominal, el Diccionario de autoridades (RAE, 1726, tomo I), en una de sus acepciones, señala:

\begin{abstract}
ALGO. Se toma tambien como advérbio, y equivale à algun tanto; pero el uso es unido à algun adjetivo precisamente: como algo escaso, algo largo, algo distante, algo alegre, y assi otros muchos exemplos, en los quales esta palabra algo significa por modo adverviál lo mismo que algun tanto. Lat. Aliquantulùm. QUEV. Tacañ. cap. 23. Se le desconcertó el relox de la cabeza, y dixo algo ronco tomando un pan con las dos manos. SOLIS, Prolog. de la Hist. de Nuev. Esp. Anduvo la verdád algo achacósa, y poco recatado el crédito de las relaciónes. CERV. Quix. tom. 1. cap. 8. Al levantarse Sancho dió un tiento à la bota, y hallóla algo mas flaca que la noche antes.
\end{abstract}

Precisamente, el último ejemplo de este diccionario recoge un extracto del Quijote: «hallóla algo más flaca». En estos casos, cuando acompaña al adjetivo se comporta como un adverbio y expresa el valor de cuantificador indefinido, que la Academia hace equivaler a «algún tanto». Es precisamente esa indefinición la que permite que se emplee en ocasiones con función atenuante. Conviene, no obstante, señalar que no cualquier uso vago del lenguaje implica automáticamente una función atenuante. De acuerdo con Albelda y Cestero (2011), Albelda et alii (2014), Albelda (2016) y Cestero (2017) -entre otros-, ha de analizarse en el contexto si su empleo se debe a motivos estratégicos para proteger o reparar un posible daño a la imagen de algún interlocutor. Obsérvese en el ejemplo (13) que Sancho emplea algo, el diminutivo en -illo en olor, para suavizar intencionadamente la calificación de lo que sintió su olfato cuando llegó junto a Dulcinea. Sin negar el valor irónico que Cervantes pretende dejar en este uso, posee un 
valor atenuante, pues el contenido del mensaje puede resultar agresivo para la imagen del interlocutor, don Quijote; lo mismo ocurre con la calificación de algo correosa:

(13) Pero no me negarás, Sancho, una cosa: cuando llegaste junto a ella, ¿no sentiste un olor sabeo, una fragancia aromática, y un no sé qué de bueno, que yo no acierto a dalle nombre? Digo, ¿un túho o tufo como si estuvieras en la tienda de algún curioso guantero?

-Lo que sé decir-dijo Sancho- es que sentí un olorcillo algo hombruno; y debía de ser que ella, con el mucho ejercicio, estaba sudada y algo correosa.

(Capítulo XxxI)

Junto con estos usos de claro carácter atenuante, de acuerdo con el cálculo del contexto, hay otros empleos en los que no es tan fácil reconocer si se trata de una intención atenuadora o si simplemente es un rasgo estilístico del autor para describir situaciones y/o crear efectos paródicos. Esto particularmente se ve en los también numerosos usos de este algo vago que, además de los protagonistas de la novela, emplea el mismo narrador. En (14) podemos apreciar cierta ironía por parte de Cervantes al describir cómo sonaba la voz de don Quijote al taparse las narices, pero al no ser un uso interaccional, tiene poco sentido el valor atenuante:

(14) Mas como don Quijote tenía el sentido del olfato tan vivo como el de los oídos, y Sancho estaba tan junto y cosido con él, que casi por línea recta subían los vapores hacia arriba, no se pudo excusar de que algunos no llegasen a sus narices; y apenas hubieron llegado, cuando él fue al socorro, apretándolas entre los dos dedos, y, con tono algo gangoso, dijo: -Paréceme, Sancho, que tienes mucho miedo.

(Capítulo xx)

Quizás no tan frecuente como algo, pero también empleado con posible valor atenuante, se registra el adjetivo cierto acompañando a sustantivos. El reconocimiento de este uso como atenuante requiere mayor atención porque se puede emplear con el valor de seguridad y certeza o de indefinición; por lo que en primer lugar hay que identificar qué valor tiene, (a) o (b), de acuerdo con el Diccionario de autoridades (RAE, 1729, tomo II):

(a) CIERTO, TA. adj. Segúro, verdadero, y libre de todo género de duda. Viene del Latino Certus, que significa lo mismo. PART. 1. tit. 4. 1. 39. E por esto les mostró Santa Eglesia cierta manéra, porque lo sopiessen facer. SANT. TER. Su Vida, cap. 8. [...]

(b) CIERTO. Significa tambien cosa no determinada: como en cierto lugár, cierta noche, \&c. Lat. Quidam, quaedam, quoddam. RIBAD. Fl. Sanct. Vida de San Gerardo. Havia, antes de esta jornada à Francia, tenido Gerardo en sueños cierta visión. ANT. AGUST. Dial. pl. 401. [...] 
Solo expresará valor vago cuando significa 'cosa no determinada' (acepción b). Una vez identificado este valor, habrá que estudiar si se emplea estratégicamente para evitar amenazar la imagen de algún interlocutor. Así, en (15) se aprecia con claridad el valor de ‘seguro' y ‘verdadero' (acepción a), por coordinarse con «claras»:

(15) nunca más le han visto reír ni hablar razón concertada, y siempre anda pensativo y triste, hablando entre sí mismo, con que da ciertas y claras señales de que se le ha vuelto el juicio.

(Capítulo XIX)

Sin embargo, en (16) expresa el significado de indeterminación (acepción b), sobre el que se aprecia, por el contexto, el valor de atenuación, al estar Sancho describiendo un atributo de su personalidad peyorativo. Aparecen, de hecho, varios mecanismos atenuantes en el enunciado: algo malicioso; ciertos asomos de bellaco. El empleo de algo en este caso también es atenuante, por el mismo motivo que lo es ciertos: introducen cualidades negativas del propio hablante que han de atenuarse para proteger su autoimagen. También el uso de asomos de en este ejemplo es atenuante, puesto que reduce la cantidad de la cualidad bellaco:

(16) -iQue todavía das, Sancho -dijo don Quijote-, en decir, en pensar, en creer y en porfiar que mi señora Dulcinea ahechaba trigo, siendo eso un menester y ejercicio que va desviado de todo lo que hacen y deben hacer las personas principales. [...] Mal se te acuerdan a ti, ;oh Sancho! aquellos versos de nuestro poeta donde nos pinta las labores que hacían allá en sus moradas de cristal aquellas cuatro ninfas que del Tajo amado sacaron las cabezas, y se sentaron a labrar en el prado verde aquellas ricas telas que allí el ingenioso poeta nos describe, que todas eran de oro, sirgo y perlas contextas y tejidas. Y desta manera debía de ser el de mi señora cuando tú la viste; sino que la envidia que algún mal encantador debe de tener a mis cosas, todas las que me han de dar gusto trueca y vuelve en diferentes figuras que ellas tienen. [...] ¡Oh, envidia, raíz de infinitos males, y carcoma de las virtudes! [...]

-Eso es lo que yo digo también -respondió Sancho- [...]. Pues a fe de bueno que no he dicho yo mal de ningún encantador, ni tengo tantos bienes, que pueda ser envidiado; bien es verdad que soy algo malicioso, y que tengo mis ciertos asomos de bellaco; pero todo lo cubre y tapa la gran capa de la simpleza mía, siempre natural y nunca artificiosa.

(Capítulo VIII)

Nos referiremos, por último, a un procedimiento atenuante de alta frecuencia hoy en día y que está ya presente en el Quijote con valor aproximativo (pero no siempre atenuante en esta obra). Se trata de la construcción como que (Cuervo 1983; Alonso 1925; Cano 1995: 126-128) y de la forma adverbial como (Cano 1995: 64 ss.). En el caso del como que aproximativo, 
Cano (1995: 127) explica que «puede superponerse a una oración completiva introducida por que (y que funciona como sujeto u objeto), matizando su valor léxico (al igual que lo hace con sustantivos, adjetivos, gerundios, etc.)». Este autor ya testimonia su aparición en textos muy anteriores a Cervantes, como obras alfonsíes o en el Corbacho. Su uso se encuentra muy extendido en la lengua actual, como se aprecia en el siguiente ejemplo (17), tomado de un corpus coloquial de lengua hablada:

(17) H0: a mí también me pasa// yo tengo debilidad/ o sea yo empatizo// y recuerdo que cuando hacía las prácticas y tal/ estaba en el instituto/// había una niña que era así súper tímida comoo o sea me recordaba mucho a mí// yy la chica se esforzaba y tal// pero le costaba no sé qué no sé cuántos// y- y parece que no pero como que intentas ahí potenciar/ reforzarla ahí para que apruebe

(Méndez, Corpus Palma, C.3./2011, líneas 322-324)

En (17), como que permite al hablante que la proposición introducida exprese un significado ambiguo o «intermedio». De acuerdo con Lakoff (1972), desde la perspectiva de la semántica formal, los hedges (es el caso de como que en 17) se emplean para no comprometerse con la verdad de un enunciado, ya que su presencia en una oración hace difusas sus condiciones de verdad. En este sentido, de lo dicho en (17) no se puede afirmar que sea verdadero o que sea falso que el hablante «intente potenciar o reforzar» a su compañera para que apruebe; el valor de verdad es intermedio y, por tanto, difuso y aproximado. Como que en este caso actúa, además, como atenuante para proteger la autoimagen de la hablante, quien pretende moderar su mérito en la ayuda que le proporcionaba a su compañera de clase.

Esta construcción se ha reconocido como elemento de lenguaje vago con antecedentes ya en el siglo XIII (Alonso 1925; Cano 1995) y con gran extensión en español (Moreno 1991; Mihatsch 2010; Jørgensen 2011; Holmvik 2011, entre otros); al igual que ya lo señaló Lakoff (1972), y luego numerosos autores (por ejemplo, Miller y Weinert 1995), para el inglés like. Cuervo (1893) y Alonso (1925: 134) reconocen ya su origen en el valor comparativo. Su valor atenuante actualmente se considera ya parte de su valor léxico, como se deriva del hecho de que se incluya en los diccionarios. Así el DRAE (23. ${ }^{\text {a }}$ ed.) señala en su octava acepción del como: «adv. Atenúa el grado de certeza de lo que se expresa a continuación. No la vi bien, pero estaba como cansada». También el Diccionario panshispánico de dudas apunta respecto a como que: «También se emplea la locución como que con valor modal o atenuativo: El niño hace como que juega; Se sentía como que había caído en una trampa».

En los ejemplos del Quijote podemos apreciar este valor de aproximación (véase también Mihatsch 2010). Alonso (1925: 134-136) habla de este 
valor «atenuativo» y considera que, según los casos, como que puede expresar un valor de semejanza, de probabilidad, de fingimiento o de ademán sincero con el que se quiere explicar el gesto que se lleva a cabo. De hecho, este último es el valor que atribuye al siguiente ejemplo (18) del Quijote:

(18) De ese parecer estoy yo -replicó el caminante-; pero una cosa, entre otras muchas, me parece muy mal de los caballeros andantes, y es: que, cuando se ven en ocasión de acometer una grande y peligrosa aventura, en que se vee manifiesto peligro de perder la vida, nunca en aquel instante de acometella se acuerdan de encomendarse a Dios, como cada cristiano está obligado a hacer en peligros semejantes; antes, se encomiendan a sus damas, con tanta gana y devoción como si ellas fueran su Dios; cosa que me parece que huele algo a gentilidad.

-Señor -respondió don Quijote-, eso no puede ser menos en ninguna manera, y caería en mal caso el caballero andante que otra cosa hiciese; que ya está en uso y costumbre en la caballería andantesca que el caballero andante que al acometer algún gran fecho de armas tuviese su señora delante, vuelva a ella los ojos blanda y amorosamente, como que le pide con ellos le favorezca y ampare en el dudoso trance que acomete; y aun si nadie le oye, está obligado a decir algunas palabras entre dientes. [...]

(Capítulo XIII)

Para Moreno Ayora (1991: 122), el valor expresado por como que en (18) consistiría en un valor mixto entre el comparativo/explicativo y el aproximativo. Aplicando la prueba para los hedges y su valor de verdad (Lakoff 1972) desde la perspectiva de la lógica modal (Lakoff 1972), no podríamos considerar ni verdadero ni falso que la mirada aludida signifique pedir que se «le favorezca y ampare en el dudoso trance que acomete». Es pues un valor intermedio, en el que ya podemos hablar de vaguedad.

El siguiente ejemplo (19), de acuerdo con Alonso (1925: 135), expresa un valor de fingimiento de un comportamiento, que en otros contextos va acompañado del verbo hacer:

(19) Y apartando a Sancho entre unos árboles del jardín y asiéndole ambas las manos, le dijo (don Quijote):

-Ya vees, Sancho hermano, el largo viaje que nos espera, y que sabe Dios cuándo volveremos dél, ni la comodidad y espacio que nos darán los negocios; y así querría que ahora te retirases en tu aposento, como que vas a buscar alguna cosa necesaria para el camino, y en un daca las pajas te dieses, a buena cuenta de los tres mil y trecientos azotes a que estás obligado, siquiera quinientos, que dados te los tendrás; que el comenzar las cosas es tenerlas medio acabadas.

(Capítulo XLI)

Por su parte, se aprecia el mismo valor de aproximación en los casos del como, que son muy cercanos a usos atenuantes actuales (vid. supra: No 
la vi bien, pero estaba como cansada). Véanse (20), (21), (22) y (23). Se mantiene parte del carácter comparativo/explicativo (al igual que expresan las construcciones «como si fuera/como si estuviera» en otros ejemplos de la obra) ${ }^{9}$ y a la vez también aproximativo (Mihatsch 2010: 80, quien asimismo cita ejemplos del Quijote), pues no se pueden evaluar los enunciados como verdaderos ni falsos:

(20) Levantado, pues, en pie don Quijote, temblando de los pies a la cabeza como azogado, con presurosa y turbada lengua, dijo [...].

(Capítulo XXXII)

(21) En tanto que el Cura decía estas razones estaba la disfrazada moza como embelesada, mirándolos a todos, sin mover labio ni decir palabra alguna...

(Capítulo XXviII)

(22) -¿Sabéis por qué, marido? -respondió Teresa-. Por el refrán que dice: «quien te cubre, te descubre!» Por el pobre todos pasan los ojos como de corrida, y en el rico los detienen

(Capítulo IV)

(23) ... dioles las cartas. Leyólas el cura de modo que las oyó Sansón Carrasco, y Sansón y el cura se miraron el uno al otro, como admirados de lo que habían leído, y preguntó el bachiller quién había traído aquellas cartas.

(Capítulo L)

En los ejemplos anteriores como actúa como modificador del adjetivo (o sintagma adjetival en 22). En los usos actuales acompaña y modifica a una mayor variedad de elementos gramaticales (adjetivos, gerundios, sintagmas adverbiales, sintagmas preposicionales, etc.): «se iban como superantes, como a las diez o así»; "van como pisando a los demás», «fue como de repente»; «él venía como a mirarme»; etc. (ejemplos tomados del corpus Colam, de conversación coloquial juvenil, Jørgensen en línea). Cano (1995: 65) registra este valor ya en textos alfonsíes, especialmente empleado ante adjetivos y participios. Para los casos en que anticipa a un gerundio señala su frecuente valor modal; por otra parte, su empleo ante sintagmas cuantificados, tan común hoy, está ya registrado por Cano (1965: 66-67) en textos medievales.

En suma, se aprecia en los mecanismos estudiados en este apartado un desarrollo profuso de la atenuación en los diálogos de la novela española

${ }^{9}$ Algunos ejemplos de la novela con como si son: como si estuviera difunta; como si fuera mudo (véase para la explicación de su valor aproximador, Alonso 1925; Fernández Ramírez 1937; Cano 1995). 
renacentista. Esta breve revisión de algunos de ellos da cuenta del comportamiento de la atenuación en la obra, y quizá de su uso en esta etapa histórica.

\section{Conclusiones}

Esta primera aproximación al estudio de la atenuación en la obra cervantina ha querido dejar constancia de cómo la presencia de este fenómeno pragmático es síntoma de madurez de la verosimilitud y naturalidad de sus diálogos. Los usos atenuantes no son esporádicos en esta novela, como sí lo son en obras un poco anteriores en el tiempo (recuérdese lo señalado en la introducción), sino que se aprecia un abundante, a la vez que variado, uso de la atenuación. Como fenómeno esencialmente interaccional, con un papel fundamental en la configuración de las relaciones sociales, el hecho de que Cervantes la emplee con verdadero dominio en su obra es manifestación, no solo de haber logrado su ideal de llaneza expresiva, sino también de reflejar una auténtica mímesis conversacional.

La dialogicidad de la literatura siempre es parcial (Bustos Tovar 2001: 198; Oesterreicher 2004: 729; Mancera 2009: 421; López Serena 2014). Sin embargo, parte esencial del logro de la simulación de esa oralidad dialogada espontánea es la «presencia mutua del yo y el tú en la construcción dialógica» (Bustos Tovar 1996: 284): «para que exista diálogo es necesario permitir que el otro se haga presente en el enunciado». Y este es uno de los cometidos fundamentales de la atenuación, puesto que se ocupa de velar por el mantenimiento de las relaciones sociales entre los interlocutores, presuponiendo las figuras de un yo y un tú. Para ello, se compensa el potencial de amenaza a las imágenes de algunos mensajes mediante la reducción de la fuerza ilocutiva (a veces también con el lenguaje vago o aproximativo). 


\section{BIBLIOGRAFÍA}

AlbeldA, Marta (2016): «Sobre la incidencia de la imagen en la atenuación pragmática», Revista Internacional de Lingüistica Iberoamericana 27, 19-32.

- y Ana M. ${ }^{a}$ Cestero (2011): «De nuevo, sobre los procedimientos de atenuación lingüística», Español Actual 96, 121-155.

- Antonio Briz, Ana Cestero, Dorota Kotwica y Cristina Villalba (2014): «Ficha metodológica para el análisis pragmático de la atenuación en corpus discursivos del español. ES.POR.ATENUACIÓN», Oralia 17, 1-44.

Alonso, Amado (1925): «Español como que y cómo que», Revista de Filología XII, 133-156.

Benavent, Elisa (2015): Decir y discurso directo en los relatos de la conversación coloquial. Tesis doctoral. Valencia: Universitat de València.

BRIZ, Antonio (1998): «Estrategias de producción-recepción: la atenuación en la conversación coloquial». En Antonio Briz, El español coloquial en la conversación. Esbozo de pragmagramática, Barcelona: Ariel, 143-163.

- (2006): «Para un análisis semántico, pragmático y sociopragmático de la cortesía atenuadora en España y América», Lingüistica Española Actual XXIX/1, $5-44$.

- y Marta Albelda (2013): «Una propuesta teórica y metodológica para el análisis de la atenuación lingüística en español y portugués. La base de un proyecto en común (ES.POR.ATENUACIÓN)», Onomázein 28, 288-319.

- y Grupo VAL.Es.Co. (2002): Corpus de conversaciones coloquiales, Madrid: Arco/ Libros.

Brown, Gillian y George Yule (1993): Análisis del discurso, Madrid: Visor Libros.

Bustos Tovar, José Jesús (1995): «La lengua clásica y Cervantes», Actas del VII Coloquio Cervantino Internacional. Guanajuato en la geografía del "Quijote», Guanajuato: Gobierno del Estado de Guanajuato, II, 15-52.

- (1996): «La construcción del diálogo en los entremeses cervantinos», en José Juan Berbel Rodríguez (coord.), En torno al teatro del Siglo de Oro, Almería: Instituto de Estudios Almerienses, 275-290.

- (2001): «De la oralidad a la escritura de la Edad Media al Renacimiento: la textualización del diálogo conversacional», Criticón 81, 191-206.

Cano Aguilar, Rafael (1995): Sintaxis histórica de la comparación en español. La historia de como, Sevilla: Secretariado de Publicaciones de la Universidad de Sevilla.

- (2005): «Estructuración Sintáctica y Construcción del Discurso en el Quijote (1605)». En R. Archer (ed.), Antes y Después del Quijote: en el Cincuentenario de la Asociación de Hispanistas de Gran Bretaña e Irlanda, Valencia: Biblioteca Valenciana, 33-57.

Cestero, Ana María (2017): «La atenuación en el habla de Madrid: patrones sociopragmáticos», RILCE. Revista de Filología Hispánica 33/1, 57-86. 
Cervantes, Miguel de (1547-1616): El ingenioso hidalgo Don Quijote de la Mancha. Edición digital basada en la edición de Madrid, Ediciones de La Lectura, 19111913. Alicante: Biblioteca Virtual Miguel de Cervantes, 1999.

Contreras, Josefa (2012): «¿Hay diferencias en las estrategias de atenuación utilizadas en los correos electrónicos españoles y alemanes?», Oralia 15, 325342.

CRIADO DE VAL, Manuel (2005): Don Quijote y Cervantes, de ayer a hoy, Guadalajara: AACHE Ediciones.

Cuervo, Rufino José (1998 [1893]): Diccionario de construcción y régimen de la lengua castellana. Continuado y editado por el Instituto Caro y Cuervo. Barcelona: Herder.

FANT, Lars (2007): «La modalización del acierto formulativo en español», Revista Internacional de Lingüistica Iberoamericana 9, 39-58.

FERnÁndez RAmírez, Salvador (1937): «Como si + subjuntivo», Revista de Filología Española XXIV, 372-380.

Fuentes Rodríguez, Catalina (1990): «Procedimientos intradiscursivos: DECIR y los explicativos». En P. Carbonero Cano (coord.), Sociolingüistica andaluza 5, 103-123.

Holmvik, Lise (2011): Como usado como marcador del discurso en el lenguaje juvenil de Madrid. Tesis de máster. Universidad de Bergen.

Humpolíková, Hana (2014): Construcción factitiva «hacer + infinitivo»: análisis de su forma, estructura y del uso práctico. Tesis doctoral, Brno: Masaryk University.

IgLESIAS BANGO, Manuel (1992): «Acerca del supuesto estatuto perifrástico de la construcción causativa hacer + infinitivo y otras cuestiones conexas (I y II)», Contexto, X/19-20, 87-148.

IgLesias Recuero, Silvia (1998): «Elementos conversacionales en el diálogo renacentista». En W. Oesterreicher, E. Stoll y A. Wesch, Competencia escrita, tradiciones discursivas y variedades lingüisticas. Aspectos del español europeo y americano en los siglos XVI y XVII, Tübingen: Gunter Narr Verlag, 385-419.

Jørgensen, Annette (2011): «Funciones del marcador pragmático como en el lenguaje juvenil español y chileno», Foro Hispánico: Revista Hispánica de Flandes y Holanda 44, 207-230.

- (dir., en línea): Corpus Oral de Lenguaje Adolescente de Madrid (COLAm), Bergen: University of Bergen.

LAKofF, George (1972): «Hedges: A study in meaning criteria and the logic of fuzzy concepts», Journal of Philosophical Logics 2, 458-508.

LAPESA, Rafael (1978): «Sobre dos tipos de subordinación causal», Estudios ofrecidos a Emilio Alarcos, 3, Oviedo: Servicio de Publicaciones de la Universidad de Oviedo, 173-205.

LÓPEZ SERENA, Araceli (2014): «De la oralidad fingida a la oralidad simuladora de realidad. Reflexiones en torno a la coloquialización del discurso como estrategia mediática», Español Actual 102, 37-73.

MANCERA RuedA, Ana (2009): «La oralidad simulada en la narrativa contemporánea», Verba 36, 419-436.

Méndez Guerrero, Beatriz (2015): Corpus Oral Juvenil del Español de Mallorca (COJEM), Lingüística en Red, Universidad de Alcalá. 
Meyer-Hermann, Reinhard (1988): «Atenuación e intensificación (análisis pragmático de sus formas y funciones en español hablado)», Anuario de Estudios Filológicos XI, 275-290.

Minatsch, Wiltrud (2007): «The construction of vagueness. 'Sort of' expressions in Romance languages». En G. Radden et alii (eds.), Aspects of Meaning Construction, Amsterdam: John Benjamins Publishing Company, 225-245.

- (2010): «Sincronía y diacronía del aproximador como», Revista internacional de Lingüistica Iberoamericana (RILI) 16, 175-201.

MILLER, Jim y Regina WEINERT (1995): «The function of LIKE in dialogue», Journal of Pragmatics 23, 365-393.

Moreno Ayora, Antonio (1991): Sintaxis y semántica de cómo, Málaga: Ágora.

Narbona, Antonio (2006): «Las voces del Quijote», Minervae Baeticae. BRASBL (Boletín de la Real Academia Sevillana de Buenas letras) 34, 161-181.

- (2007): «Sintaxis de la escritura de lo oral en los diálogos del Quijote». En Discurso y oralidad. Homenaje al profesor José Jesús de Bustos Tovar, I, Anejos de la revista Oralia 3/1, Madrid: Arco/Libros, 65-107.

- (2015): Sintaxis del español coloquial, Sevilla: Editorial Universidad de Sevilla.

- (2017): «El diálogo de igual a igual entre don Quijote y Sancho». En A. Asensi (ed.), Miguel de Cervantes (1616-2016), Málaga: Instituto de Academias de Andalucía/Consejería de Economía y Conocimiento de la Junta de Andalucía, 29-48.

OESTERREICHER, Wulf (2004): «Textos entre inmediatez y distancia comunicativas. El problema de lo hablado escrito en el Siglo de Oro», en R. Cano (coord.): Historia de la lengua española, Barcelona: Ariel, 729-757.

Pujante, David (2007): «Planteamientos retóricos en El Ingenioso Hidalgo Don Quijote de la Mancha de Miguel de Cervantes». En M. V. Utrera Torremocha y M. Romero Luque (eds.), Estudios literarios in honorem Esteban Torre, Sevilla: Secretariado de Publicaciones de la Universidad de Sevilla, 609-625.

Real Academia de la Lengua Española (1726-1739): Diccionario de Autoridades, Madrid: Instituto de Investigación Rafael Lapesa y la Real Academia Española.

- (2005): Diccionario panhispánico de dudas, Madrid: Espasa.

- (2014): Diccionario de la Lengua Española, 23. ${ }^{a}$ ed., Madrid: Espasa.

Real Academia de la Lengua Española y Asociación de Academias de la Lengua ESPAÑOLA (2009): Nueva gramática de la lengua española, Madrid: Espasa.

Reig Alamillo, Assela (2006): «Una clasificación de los verbos realizativos en español». En T. L. Face y C. A. Klee (eds.): Selected Proceeding of the 8th Hispanic Linguistics Symposium, Somerville, MA: Cascadilla Proceedings Project, 183190. <www.lingref.com, document \#1265>.

- (2007): «Los verbos realizativos, la situación comunicativa y los actos declarativos de Searle», Pragmalingüistica 15-16, 179-199. <http://revistas.uca.es/ index.php/pragma/article/view/11/11>.

SCHNEIDER, Stefan (2013): «Atenuación léxica y sintáctica», Oralia 16, 335-356.

THALER, Verena (2012): «Mitigation as modification of illocutionary force», Journal of Pragmatics 44, 907-919. 